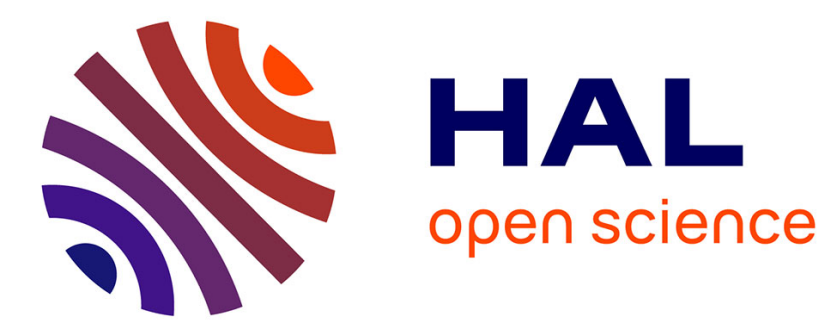

\title{
Electrochemical conversion of glassy carbon into a poly-nucleophilic reactive material. Applications for carbon chemical functionalization. A mini-review
}

Viatcheslav Jouikov, Jacques Simonet

\section{- To cite this version:}

Viatcheslav Jouikov, Jacques Simonet. Electrochemical conversion of glassy carbon into a polynucleophilic reactive material. Applications for carbon chemical functionalization. A mini-review. Electrochemistry Communications, 2014, 45, pp.32-36. 10.1016/j.elecom.2014.05.015 . hal-01151720

\author{
HAL Id: hal-01151720 \\ https://hal.science/hal-01151720
}

Submitted on 25 Mar 2016

HAL is a multi-disciplinary open access archive for the deposit and dissemination of scientific research documents, whether they are published or not. The documents may come from teaching and research institutions in France or abroad, or from public or private research centers.
L'archive ouverte pluridisciplinaire HAL, est destinée au dépôt et à la diffusion de documents scientifiques de niveau recherche, publiés ou non, émanant des établissements d'enseignement et de recherche français ou étrangers, des laboratoires publics ou privés. 


\section{Accepted Manuscript}

Electrochemical conversion of glassy carbon into a poly-nucleophilic reactive material. Applications for carbon chemical functionalization. A mini-review

Viatcheslav Jouikov, Jacques Simonet

PII:

S1388-2481(14)00147-7

DOI:

doi: 10.1016/j.elecom.2014.05.015

Reference: $\quad$ ELECOM 5160

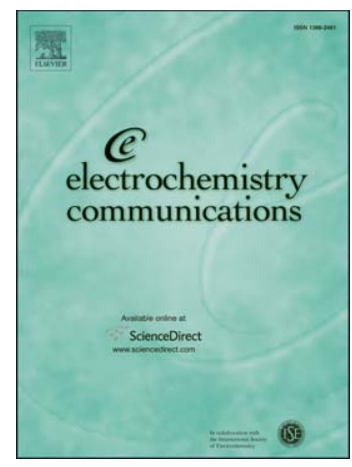

To appear in: Electrochemistry Communications

Received date: $\quad 7$ May 2014

Revised date: $\quad 9$ May 2014

Accepted date: $\quad 9$ May 2014

Please cite this article as: Viatcheslav Jouikov, Jacques Simonet, Electrochemical conversion of glassy carbon into a poly-nucleophilic reactive material. Applications for carbon chemical functionalization. A mini-review, Electrochemistry Communications (2014), doi: 10.1016/j.elecom.2014.05.015

This is a PDF file of an unedited manuscript that has been accepted for publication. As a service to our customers we are providing this early version of the manuscript. The manuscript will undergo copyediting, typesetting, and review of the resulting proof before it is published in its final form. Please note that during the production process errors may be discovered which could affect the content, and all legal disclaimers that apply to the journal pertain. 


\title{
Electrochemical conversion of glassy carbon into a poly-nucleophilic reactive material. Applications for carbon chemical functionalization. A mini-review.
}

\author{
Viatcheslav Jouikov and Jacques Simonet ${ }^{\mathrm{b} *}$ \\ a) CPM, UMR 6226, Université de Rennes 1, Campus de Beaulieu, 35042 \\ Rennes Cedex, France. \\ b) Laboratoire MaSCE, UMR 6226, Université de Rennes 1, Campus de \\ Beaulieu, 35042 Rennes Cedex, France
}

\begin{abstract}
During the last decade, various carbon modifications were achieved via radical addition of substituted aryl radicals produced at the surface by chemical or/and electrochemical reduction of corresponding aryldiazonium salts. Very recently, surface reactivity of carbons towards electrophilic halo-derivatives with long alkyl chains had been developed. Surface nucleophilicity of carbons was induced by their specific cathodic charge (at $\mathrm{E}<-1.7 \mathrm{~V}$ in non-aqueous electrolytes) affecting the nano-crystallites (mainly graphite) contained in glassy carbons due to the mode of its manufacturing (high temperature carbonization of phenolic resins). This new paradigm of surface decoration was successfully applied using alkyl halides, carbon dioxide, dioxygen, sulfonyl chlorides etc. and proved efficient with allotropic varieties of carbon (in particular graphites and graphene).
\end{abstract}

Key words: Glassy carbon; Poly-nucleophile; Surface modification via $\mathrm{S}_{\mathrm{N}} 2$; Alkylation; Carboxylation

\section{Introduction}

For the electrochemical community, glassy carbon (GC) is primarily a convenient electrode material for carrying out analyses and electrolyses within the cathodic range [1-2]. Very often, this material was considered as non-reactive and was used as an advantageous substitute of mercury and platinum [3]. However, most of the materials named glassy carbons, produced by carbonization of phenolic resins [4] at temperatures up to $2500{ }^{\circ} \mathrm{C}$, were reported to contain large amounts of graphite-like inclusions. They should therefore be regarded as complex materials containing reticulated $\mathrm{C}_{\mathrm{sp} 3}$ zones in contact with the areas where $\mathrm{sp}^{2}$ carbon atoms predominate. Recent studies, focalized on large nano- and micro-inclusions of graphitized, graphenized, and fullerenized incorporates in the body of tetrahedral carbons, emphasize this point [5-6]. Structure and conductivity of commercial GCs are thus strongly dependent on the mode of their manufacturing and especially on the carbonization temperatures. There follows that common glassy carbons correspond to complex redox conglomerates gathering aromatic structures that provide the conductivity by electron hopping between them. 
As a matter of fact, in polar aprotic solvents most of GCs can show own cathodic response very similar to that of highly oriented pyrolytic graphite (HOPG) and more generally to that of natural graphites. Thus, under cathodic polarization, graphites are well known to be charged with $\mathrm{Li}^{+}$[6]. More recently, HOPG was reversibly charged (or "reduced") in the presence of tetraalkylammonium salts (TAAX) to form intercalation compounds leading to well-defined structures depending on applied potentials $(\mathrm{E}<-1.7 \mathrm{~V} v s . \mathrm{Ag} / \mathrm{AgCl})$ and on the bulkiness of $\mathrm{TAA}^{+}$cations used [7]. These carbon insertion stages $\left[\mathrm{C}_{\mathrm{p}}^{-}, \mathrm{TAA}^{+}\right]$formed by electron uptake and concomitant insertion of tetraalkylammonium salts were considered as "graphite salts", rather similar to TAA amalgams, and used (under inert atmosphere) as reducing species and poly-nucleophilic materials. Large exfoliation of graphite [8] and subsequently the exposure of the formed carbon salts, acting as nucleophilic species, to $\mathrm{CO}_{2}$ permitted, for the first time, carboxylating HOPG to a large extent [9].

Electrochemical properties of HOPG can easily be transposed to GC, almost counter-intuitively bearing out that the latter can manifest a great deal of interfacial reactivity of graphite. In other words, GC surface could be perceived as a zone with strong nucleophilic reactivity when quite negative potentials $(-1.7 \mathrm{~V})$ are reached. In fact, this is not so surprising when considering aromatic inclusions in GC as more loaded congeners of benzenoid aromatics (benzene, anthracene etc) whose reduction to give nucleophilic species is well documented [10]. Therefore, the reactivity of GC interface (ET versus $\mathrm{S}_{\mathrm{N}}$ 2-like reactions) toward electrophilic organic derivatives is worth being re-considered. Given the above said, new paradigm of nucleophilic modification of carbons can be developed using this chemistry.

\section{Evidence of cathodic charge of carbons at $E<-1.7 \mathrm{~V}$}

The presence of graphite nano-crystallites in many kinds of glassy carbons is well-recognized [1], but the intrinsic cathodic behaviour of GC (i.e. its cathodic charge, principally in the interfacial area) is rarely considered or taken into account. A specific charge/discharge process beyond $-1.7 \mathrm{~V}$ at a Carbone-Lorraine GC macro-electrode helps to interpret the way of trapping primary alkyl iodides [11]. Figure 1 A exhibits the charge of such CG electrodes as compared to curves B where a much poorer in (but not void of) $\mathrm{C}_{\mathrm{sp} 2}$ inclusions $\mathrm{GC}$ surface is covered by a thin layer of natural graphite (curve 2). The almost perfect correspondence of voltammetric responses in A and B2 is striking. Let us remark that a large presence of graphite in GC would provide an advantage for obtaining very dense coverages of grafting on carbons. Charging phenomenon, analogous to that of graphite, was also observed for graphenes deposited on carbons (and also on $\mathrm{Au}, \mathrm{Ag}, \mathrm{Cu}$ or $\mathrm{Pt}$; in the latter case, very dry organic solvents are needed). However, fullerenes and carbon nanotubes did not exhibit any cathodic charging before $-2.3 \mathrm{~V}$ [12] because surface-related ion-pairing in these systems, akin to the stabilization of the anion radicals of aromatic hydrocarbons by cations of the supporting salts [13], is less 
efficient for negative charge stabilization than charging with in-depth $\mathrm{TAA}^{+}$ insertion.

The influence of a large incorporation of graphite (or graphene) in the GC may quite certainly influence reduction potentials of acceptors (here, electrophiles like 1-iodoalkanes [14]) in non-aqueous solvents as shown in Figure 1, C1-C2. This undermines a widespread view of GC as an almost perfect material without any catalytic activity compared to other electrode materials such as silver, palladium or copper. Thus, curve $\mathrm{C} 1$ (Tokai carbon having lower graphite content) has $\mathrm{E}_{1 / 2}=-1.92 \mathrm{~V}$ while graphite-reach GC (Carbone-Lorraine) provokes an anodic shift, $\mathrm{E}_{1 / 2}=-1.78 \mathrm{~V}$. In the latter case $(\mathrm{C} 2)$, the threshold of graphite charging and the reduction potential of 1-iodoalkane are identical $(-1.6 \mathrm{~V})$ meaning that graphite charge may induce a kind of redox-catalytic interface. This assumption was entirely verified with gold electrodes with deposited thin layers of natural graphite or graphene.

\section{Surface modifications based on GC cathodic charge}

Nucleophilic surface modification of GC takes on different aspects: i) an irreversible prodding of the initial surface by charge, ii) $\mathrm{TAA}^{+}$cation insertion to burst the graphite inclusions in the vicinity of the surface along with iii) chemical reactivity of nano-nucleophilic centres disposed at (or very close to) the interface. This phenomenon has been clearly demonstrated [9] during the charge of HOPG in the presence of $\mathrm{CO}_{2}$ in N,N-dimethylformamide (DMF) using several $\mathrm{TAA}^{+}$ cations. Consequently, one may expect the formation of a quite rough surface until a thick semi-porous interface is created leading to apparent superficial concentrations of the grafted groups up to hundred times the values expected for perfectly smooth surfaces. These main features are illustrated in Figure 2, part 1. The inherent to this process "over-grafting" was often interpreted by certain reviewers as indicating "multilayer" configurations of the immobilized layers.

The creation of poly-nucleophilic micro volumes remains for us the key to the surface reactivity excluding, therefore, the implication of radical chemistry at the potentials of GC charging; this is a principal difference opposing nucleophilic surface modification to the grafting of aryl radicals [15] generated at $\mathrm{E}>-1 \mathrm{~V}$. Several two-steps processes demonstrate this: charging $\mathrm{GC}\left(10^{-3} \mathrm{C} \mathrm{mm}^{-2}\right)$ followed by its transfer (under argon) to another vessel containing the solution of an electrophile to react for 10-20 s. Figure 2, part 2 exemplifies these $\mathrm{S}_{\mathrm{N}} 2$-type reactions with $\omega$-iodoalkylferrocenes, sulfonyl chlorides and carbon dioxide where the immobilization of specific redox groups could be shown.

\section{Mechanism and examples of surface functionalization}

Once the GC superficial zone is cathodically charged (Scheme 1, reaction I), its $\left[\mathrm{C}_{\mathrm{p}}^{-} \mathrm{TBA}^{+}\right]$sites can act both as nucleophilic and as reducing species towards electrophilic substrates RX present at this interface. Two pathways are then possible: electron transfer (path II) or an $\mathrm{S}_{\mathrm{N}} 2$ reaction (path III). Let us underline 
that beyond the potential of the threshold of carbon charging, the stability of free radicals is low and their specific immobilization is improbable.

Scheme 1 summarizes several type III surface nucleophilic displacement reactions [16]. The immobilization of $\mathrm{CO}_{2}$ [17], which can be realized on most types of carbons (including graphite and graphene), enables a facile synthesis of poly-carboxylated GC eventually covered with graphene [22]; strongly hydrophilic, such interfaces can be readily transformed into redox materials by simple reactions of the carboxylate group. Also, the use of non-Kolbe oxidation of the polycarboxylate $($ at $+1.3 \mathrm{~V}$ ) easily allows [12] the efficient conversion of GC into a poly-electrophilic material with a wide range of interesting reactions that could be regarded as a new chapter in the field of surface electrophilic displacement reactions. Deposition of graphene onto solid surfaces (GC, Au, Ag) followed by carboxylation led to three-dimentional electrodes with functional properties easily tuneable by ensuing chemical modification [23].

Besides the surface modifications displayed in Scheme 1, part B, several similar functionalizations of GC were shown [12] to occur. For example, let us quote a series of functional bromoalkanes $\mathrm{Br}-\left(\mathrm{CH}_{2}\right)_{\mathrm{n}}-\boldsymbol{F}(\mathrm{n}>2)$ with $\boldsymbol{F}$ being $\mathrm{CN}$, $\mathrm{NH}_{2}, \mathrm{OH}$, and aryl groups. The sole condition for the choice of the function $\boldsymbol{F}$ is that it should not be reducible prior to $\mathrm{GC}$ charge.

Lastly, $\alpha, \omega$-diiodoalkanes $\left(\mathrm{X}-\left(\mathrm{CH}_{2}\right)_{\mathrm{n}}-\mathrm{X}\right.$ with $\left.\mathrm{X}=\mathrm{I}\right)$ can be used for immobilization of graphene or nano-graphite flakes onto GC at potentials where both GC and graphene are charged. Such an interface could be considered as a kind of redox polymer [24] quite obviously suitable for further modifications using multiple reactive possibilities of graphene (see Scheme 1, C).

\section{Conclusion}

The present compilation accentuates the possibility of taking advantage of the electrochemical charge of glassy carbons at $\mathrm{E}<-1.7 \mathrm{~V}$ using polar organic solvents containing non-electrophilic TAAX salts and aiming specific surface modification for unsaturated fractals are unavoidably present in such materials. The series of nucleophilic surface-related reactions (recalled or reported for the first time in this study) was possible due to the inclusions of graphite, graphene, and fullerene-like structures in carbon. Special care was taken to connect the cathodic reactivity of carbon to that of graphite and graphene deposited in very thin layers not only on GC but also on gold or silver. We stress the usefulness of this process for creating poly-nucleophilic materials (in mass or in thin (or ultra thin) supported layers) that offer -under quite simple conditions and using commercially available electrophilic reagents- very wide possibilities. Expanding the preliminary observations made with GC (published since the end of 2011), a very large panel of possibilities obviously emerges from using graphite(s) and graphene(s), especially underlaid with metals. Work in progress could underline the interest of this approach in electrochemistry and materials science. 


\section{Experimental section}

6.1. Electrode materials: Carbon samples were purchased from Tokai Carbon Co (GC Rod) and from Carbone-Lorraine (large plates, VD 1500 and 2500, $3 \mathrm{~mm}$ thick). Polishing of GC was achieved with Struers waterproof silicon carbide papers (P\#500 and then \#1200) and Emery papers 02 and 03. After polishing, the electrodes were sonicated for eliminating grease and carbon dust.

Solid materials (GC, gold) could as well be used (for comparison) for deposition of graphite and graphene.

6.2. Solvents and electrolytes: Voltammetry discussed in the present review mostly concerns the solutions of tetra- $n$-alkylammonium salts $(0.1 \mathrm{M})$ in DMF. Solvents and salts (Aldrich) were used as received. All the experiments described here did not need special treatments of the electrolytic solutions.

6.3. Electrochemical experiments: All potentials are referred to aqueous $\mathrm{Ag} / \mathrm{AgCl} l_{\text {(sat) }}$ placed in a bridge containing the corresponding \{solvent/electrolyte\} solution. The electrochemical instrumentation has been previously reported [22].

Most of electrodes used had an apparent surface area of $0.8 \mathrm{~mm}^{2}$. Coulometric measurements and electrolyses were carried out using separated with fritted glass three-electrode cells with a total catholyte volume of about 5 to $7 \mathrm{~mL}$. Argon bubbling was completed in all experiments. Modified electrodes were sonicated during $2 \mathrm{~min}$ in water and then rinsed with acetone.

\section{References}

[1] R. L. McCreery, Chem. Rev., 108 (2008) 2646.

[2] H. J. Schäfer in Comprehensive Organic Synthesis, Vol. 3 (Eds. B.M. Trost, I. Fleming), Pergamon Press, New York, 1991, p. 633.

[3] D.G. Peters, in Organic Electrochemistry (Eds. H. Lund, O. Hammerich), M. M. Dekker, New York, Basel, (2001) 341.

[4] G.M. Jenkins, K. Kawamura, Nature, 231 (1971) 175.

[5] P.J.F. Harris, Philosophical Mag., 84 (2004) 3159.

[6] P. Bernier, S. Lefrant, Le carbone dans tous ses états, Gordon and Breach Science Publishers, Amsterdam, (1997), and references cited.

[7] J.O. Besenhard, Carbon, 14 (1976) 111.

[8] J. Simonet, H. Lund, J. Electroanal. Chem., 77 (1977) 719.

[9] C. Dano, J. Simonet, J. Electroanal. Chem., 564 (2004) 115.

[10] J. Heinze, in Organic Electrochemistry (Eds. H. Lund, O. Hammerich), M. M. Dekker, New York, Basel, (2001) 293.

[11] V. Jouikov, J. Simonet, Langmuir 28 (2012) 931.

[12] J. Simonet, unpublished observations.

[13] B.S. Jensen, V.D. Parker, J. Amer. Chem. Soc., 97 (1975) 5211.

[14] J. Simonet, Electrochem. Commun., 13 (2011) 107.

[15] D. Bélanger, J. Pinson, Chem. Soc. Rev. 40 (2011) 3995.

[16] J. Simonet, Electrochem. Comm., 13 (2011) 107. 
[17] J. Simonet, Electrochem. Comm., 21 (2012) 22.

[18] P. Poizot, J. Simonet, , Electrochem. Comm., 23 (2012) 137.

[19] V. Jouikov, J. Simonet, Electrochem. Comm., 23 (2011) 1296.

[20] D. Lorcy, K.-S. Shin, M. Guerro, J. Simonet, Electrochim. Acta, 89 (2013) 784.

[21] J. Simonet, Electrochem. Comm., 21 (2013) 223.

[22] V. Jouikov, J. Simonet, Electrochem. Comm., in press.

[23] V. Jouikov, J. Simonet, Electrochem. Comm., 42 (2014) 34.

[24] J. Simonet, Electrochem. Comm., 36 (2012) 62. 


\section{Figure captions}

\section{Figure 1}

Voltammetry of glassy carbons under cathodic charge. DMF / $0.1 \mathrm{M} \mathrm{Et}_{4} \mathrm{NBF}_{4}$. Scan rate $50 \mathrm{mV} \mathrm{s}^{-1}$. (A) Carbone Lorraine GC electrode $\left(7 \mathrm{~mm}^{2}\right)$. (B) Poorer in graphite Tokai GC: bare (curve 1) and covered by an ultra thin layer of natural Ceylon graphite (curve 2). (C) Reduction of 1-iodo-octane $\left(11 \mathrm{mmol} \mathrm{L}^{-1}\right)$ at two different GCs. (C1) Tokai GC $\left(0.8 \mathrm{~mm}^{2}\right)$; (C2) Carbone Lorraine GC $\left(7 \mathrm{~mm}^{2}\right)$.

\section{Figure 2}

(1) Cathodic charging of GC with progressive swelling and exfoliation caused by insertion of $\mathrm{TAA}^{+}$into surface-located graphitic inclusions.

(2) Charge of GC and its reactivity with electrophilic reagents $\left(10^{-2} \mathrm{~mol} \mathrm{~L}^{-1}\right.$ in DMF) after transferring (under argon) to another flask. The voltammograms illustrate specific responses of the grafted redox groups after sonication of the modified electrodes. DMF / 0.1 $\mathrm{M} \mathrm{Et}_{4} \mathrm{NBF}_{4}$.

\section{Scheme 1}

Modification of GC surfaces by means of miscellaneous electrophilic reagents: A) General mechanism; B) Some examples of grafting through $\mathrm{S}_{\mathrm{N}} 2$ surface processes (see text); C) Immobilization of graphene particles at GC surface via $\alpha, \omega$-diiodoalkanes. 


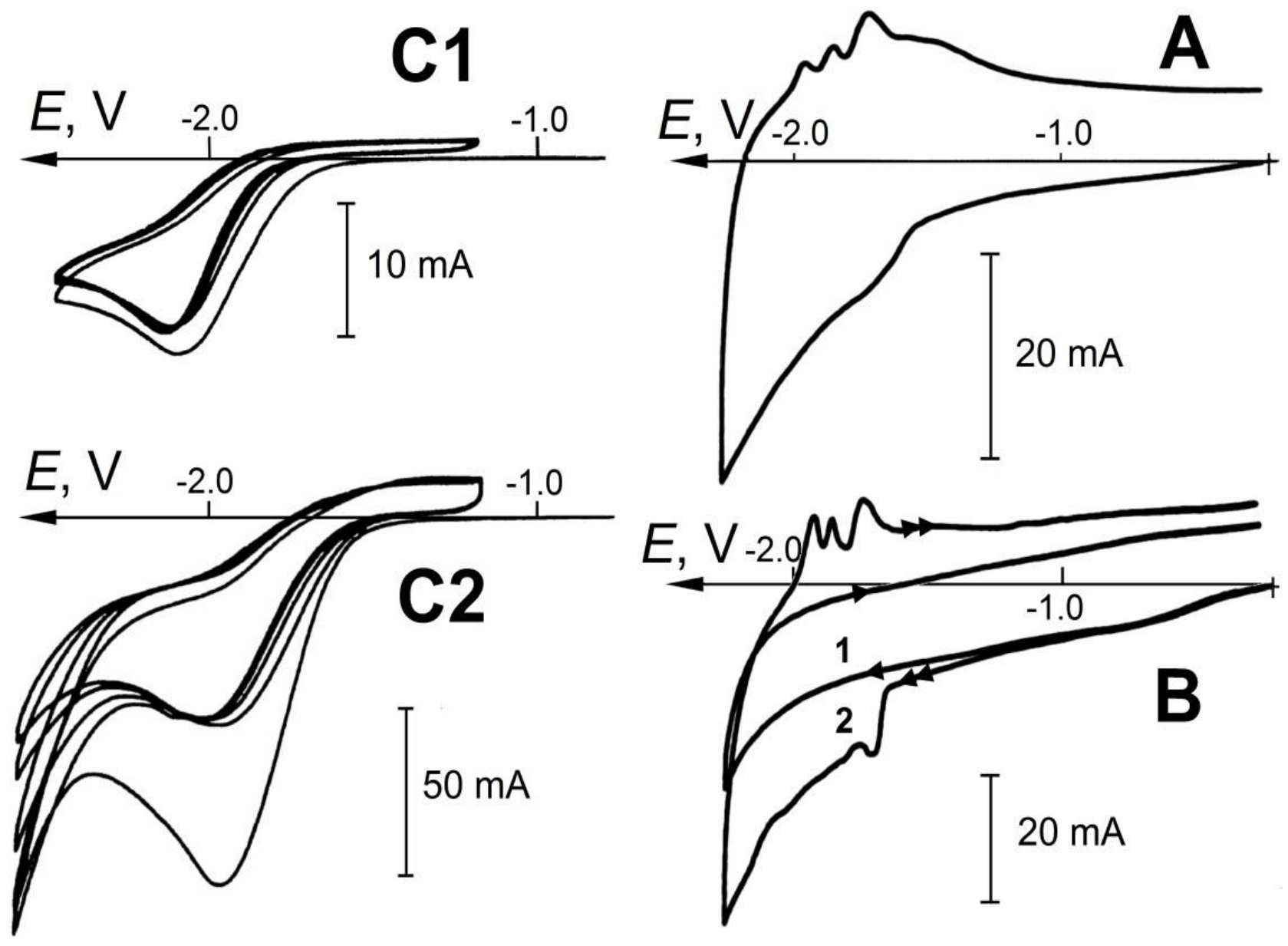

Figure 1 


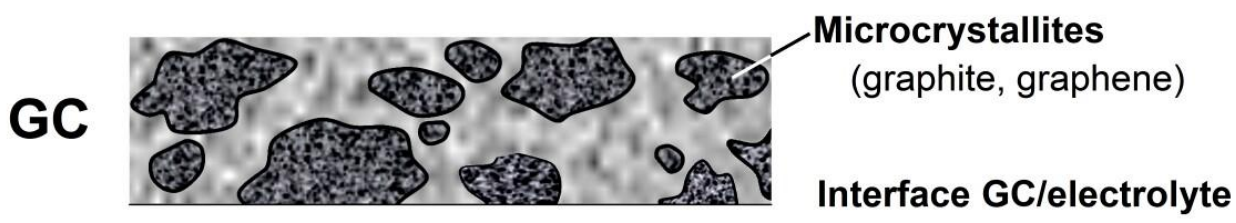

$$
\begin{array}{r}
\text { Cathodic charge + exfoliation via TAA } \\
\text { surface swelling }
\end{array}
$$

GC

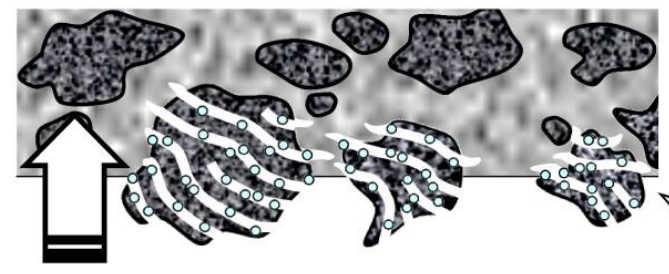

Front of cathodic erosion upon time and applied potential

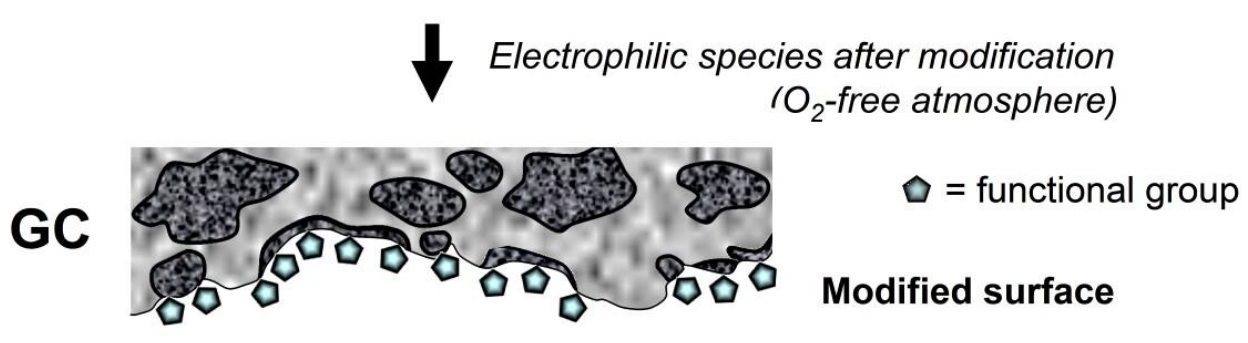

Part 1.

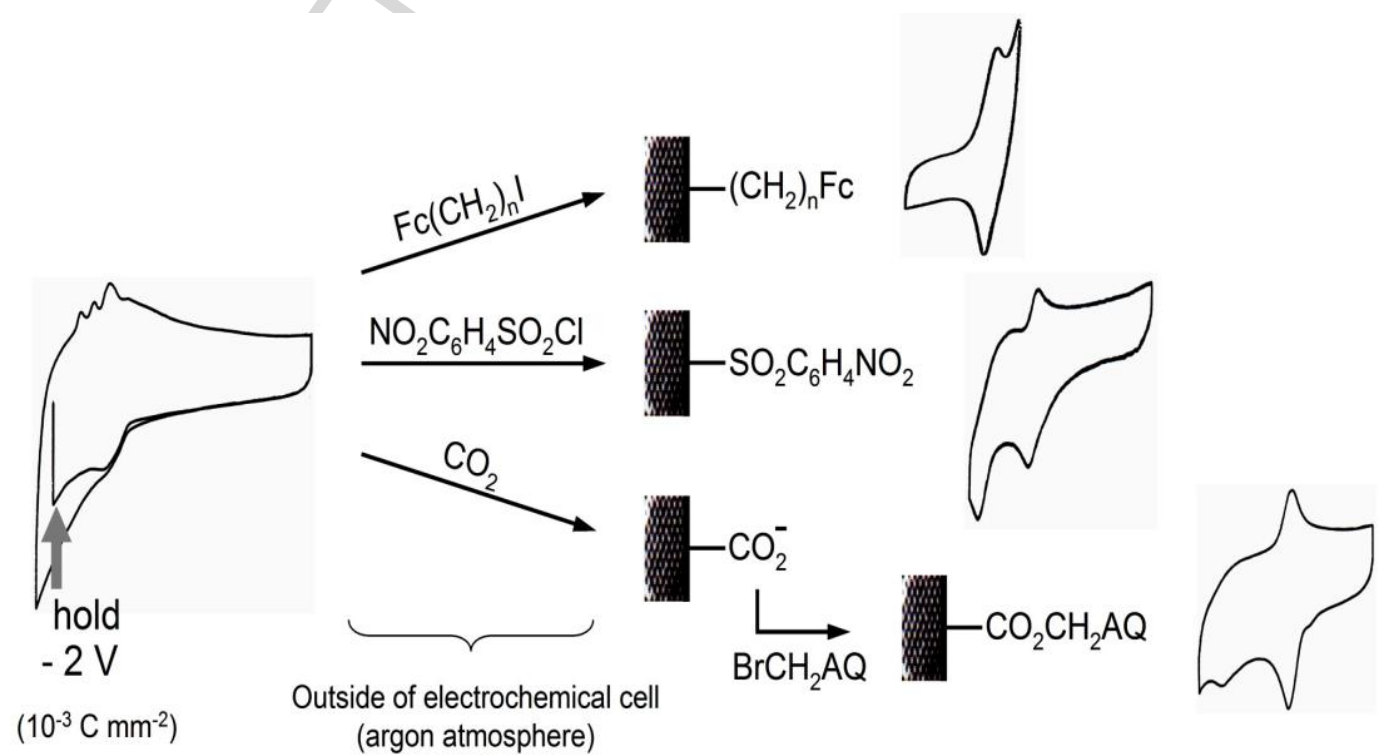

Part 2

Figure 2 


$$
\text { A } \quad\left[{ }^{[}\right]_{m} \underset{m}{\stackrel{\text { Charge }(e+\text { TBAX })}{\text { Graphitized zones }}}\left[{ }^{-}{ }^{-} \mathrm{TBA}^{+}\right]_{\mathrm{m}}
$$

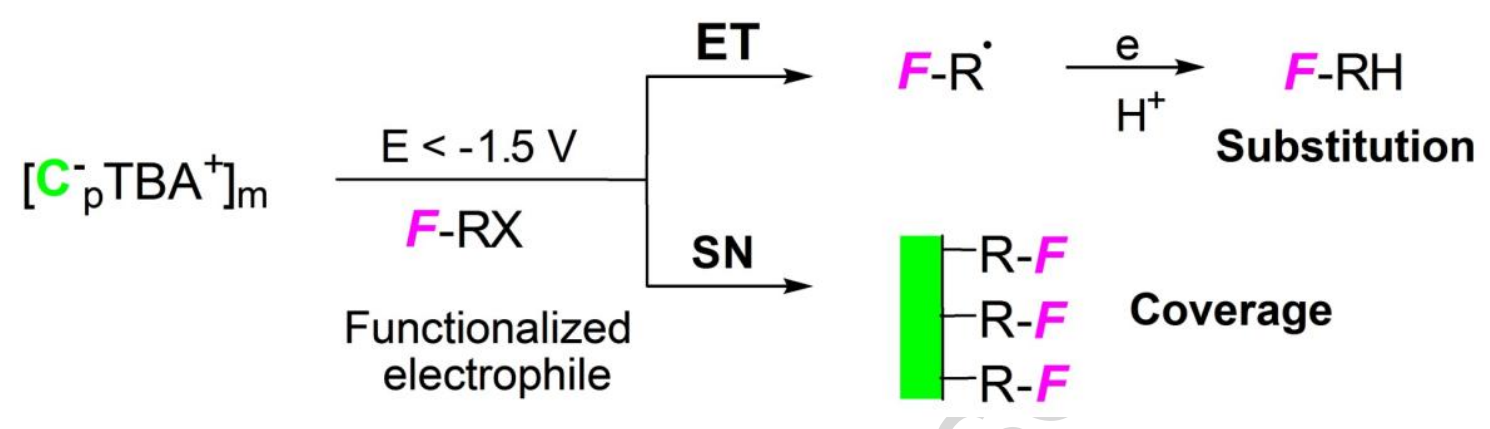
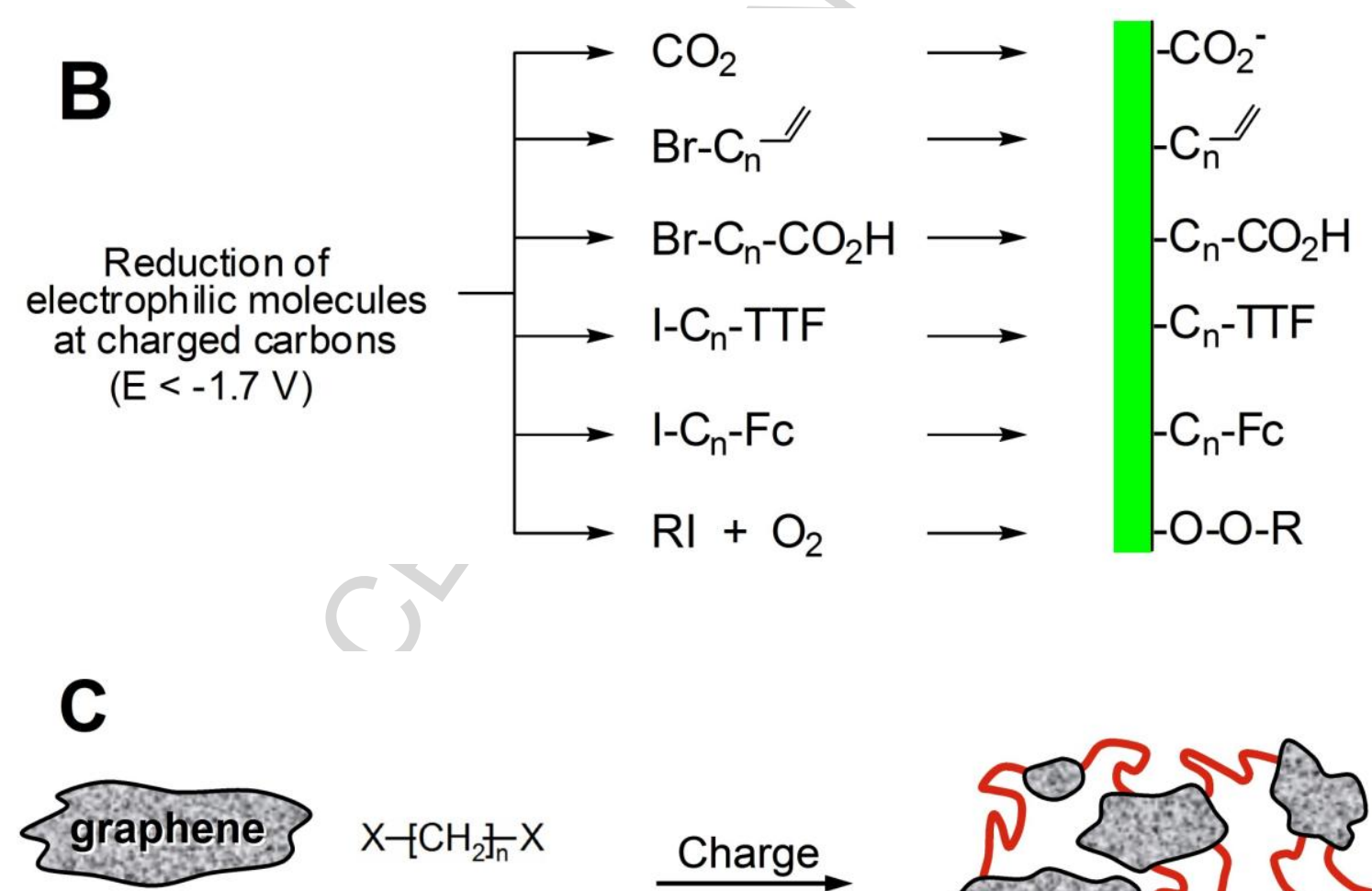

Glassy carbon
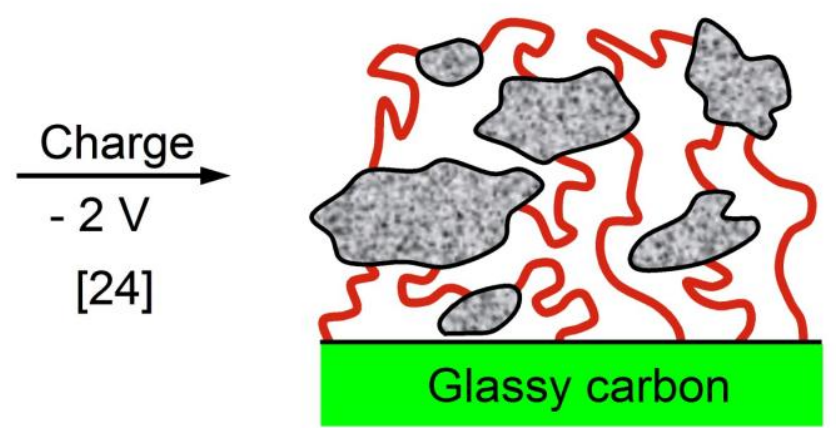

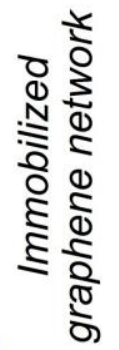

Scheme 1 

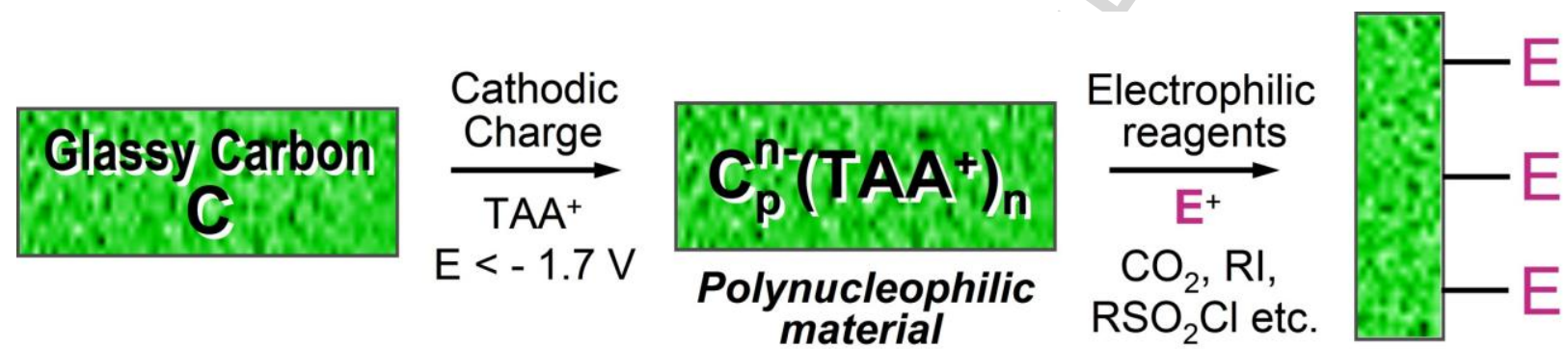

Graphical Abstract 


\section{Highlights}

A new process based on the cathodic charge of carbons at the potential $\mathrm{E}<-1.7 \mathrm{~V}$ vs. $\mathrm{Ag} / \mathrm{AgCl}>\mathrm{In}$ aprotic organic solvents containing non-electrophilic salts (for example: tetraalkyammonium salts), the charge of carbons permits creating poly-nucleophilic materials with high reactivity of the interface > In the contact with electrophilic organic reagents (such as $\mathrm{CO}_{2}$, organic acid halides, functionalized alkyl halides, etc...), nucleophilic reactivity of charged carbon leads to specific modified interfaces. 